\title{
LA TECNOLOGÍA, INTERNET Y REDES SOCIALES EN LA VIDA DE LOS NIÑOS, NIÑAS Y ADOLESCENTES. ${ }^{1}$
}

\author{
TECHNOLOGY, THE INTERNET, AND SOCIAL NETWORKS IN THE \\ LIVES OF CHILDREN AND ADOLESCENTS
}

José Jhonatan Hernández López*

\section{Resumen:}

El autor de esta ponencia es una adolecentes quien desde su propia perspectiva comparte su visión al mundo sobre cómo la tecnología y las redes sociales influyen en la familia, el rol de los padres y sobre todo en los niños, niñas y adolecentes.

Palabras Claves: familia, tecnología, redes sociales, niños, niñas y adolecentes.

\begin{abstract}
The author of this presentation is a teenager who from his own perspective shares his vision to world how technology and social networks influence the family, the role of the parents and especially the childrn and teenagers.
\end{abstract}

Keywords: family, technology, social networks, children, teenagers.

\footnotetext{
Ponencia presentada en el Pre Congreso Mundial de los Derechos de la Niñez y la Adolescencia organizando por el Colegio de Abogados de Lima y llevado a cabo el 7 y 8 de sitiembre de 2018.

* Representante de la "Red Distrital de Municipios Escolares de Lima Sur". Conductor del Programa Radial Distrital "Sin Rollos ni Paltas" / Villa El Salvador / 2013-2017.
} 
El ser humano ha ido evolucionando a lo largo de su vida, implicando cambios en su misma convivencia y en el modo de captar la sociedad.

En la era antigua los Niños, Niñas y Adolescentes (en adelante los NNA) osaban jugar con algunas piedras, huesos y animales.

En la era intermedia los NNA se entretenían con juegos físicos de colores llamativos o con objetos ruidosos.

En la era actual los NNA han dejado atrás todo esto para someterse al mundo de la ciencia, no solo dejando el mundo físico sino también causando un desapego social (familia, amigos, etc.).

Los padres, quienes supuestamente son el primer factor de desarrollo para los NNA (educación, moral, espiritual, social, etc.), no están cumpliendo con su real función; sino que piensan que los "aparatos del futuro" pueden reemplazar sus funciones. "Ahora nos dan un teléfono celular o una Tablet para no fastidiarlos cuando están ocupados". "Ahora solo nos dicen que nos quieren por nuestras redes sociales". "Ahora demuestran lo que sientes con emoticonos". "Ahora solo interactuamos con las cosas y animales mediante videos"; dejando de lado los cuidados y la protección que nos merecemos.

Está de más mencionar los beneficios que nos trae todo esto, porque lo pueden buscar por el mismo internet; en cambio, nuestra realidad no. Lo que pensamos y sentimos los NNAs no se encuentra allí.

En la tecnología, internet y redes sociales encontramos muchos peligros, de los cuales estamos vulnerables: desde desapego hasta violación y muerte (bullying, ciberbullying, acoso sexual, trata de personas; baja autoestima por falta de atención, falta de cuidados, desprotección, falta de educación de valores morales, inserción de ideologías ajenas, etc.) y muchos más.

El Estado, cumple un rol muy importante al ser el principal velador de los derechos humanos, los derechos del ciudadano, los derechos de los NIÑOS, NIÑAS Y ADOLESCENTES. Sin embargo, lamentablemente no los cumple a totalidad, El Estado debe ser el mayor regulador de las informaciones que se exponen en la internet y en las redes sociales, y brindar severos castigos para quienes las usen con otros fines; debe crear políticas públicas de prevención, detención y sanción, para llegar a los NNA desde los colegios informándonos los peligros que contrae el mal uso de éstas, y a los adultos para que puedan detectar y ayudarnos. 
La tecnología, internet y redes sociales van en progreso y lo seguirán haciendo; mientras que nosotros estaremos dependiendo de ellas cada vez más; no perdamos la esencia de ser padres, de ser familia, de ser amigos, de ser hijos, de ser ciudadanos, porque si lo hacen el mundo estaría perdido; y nos preguntaremos ¿conectados o atrapados?, ¿en avance o en retroceso?

LOSNIÑOS, NIÑAS Y ADOLECENTESTEQUEREMOS... YTÚ ¿TAMBIEN?

Fecha de recepción $\quad$ : 27 de agosto de 2018

Fecha de aceptación : : 26 de octubre 2018 